\title{
Combined reconstruction using cross leg flap and cross-Ilizarov external fixator in treatment of distal third tibial post-traumatic bone and soft time injuries
}

\author{
Mahmoud M Fayed, $M D^{(a)}$; Sherien M Salama, $M D^{(b)}$
}

(a) Orthopedic Department, Ain Shams University, Egypt.

(a) Plastic Surgery Department, Ain Shams University, Egypt.

Background: Combined trauma of the lower third leg of Gustilo grade (GIII) B-C open tibia shaft fractures have a wide spectrum of injury to the bone and soft tissues.

Objective: To evaluate the outcome of using Ilizarov external fixator and cross leg flap in patients with combined traumatic (GIII) B-C open lower third tibial fractures.

Patients and methods: This prospective study was conducted between 2008 and 2012 on 9 male patients of age between 18 to 42 years (average 37years). 4 patients were of Gustilo type IIIB with extensive periosteal stripping and 5 patients of Gustilo type IIIC. 2 patients were acute trauma (6-12) hours and 6 presented late (2-5 months after injury). Exposure of bone and/or hardware was the major problem in these patients. Nerve injury was negative in all patients. A protocol for sequential staged reconstruction and preoperative planning was arranged by the orthopedic and plastic surgeon in all cases. We used random pattern fasciocutaneous cross leg flap as soft tissue cover along with modified 3/8 Ilzarov frame (modified by orthopedic author) for tibial fracture with or without bone defect. Total treatment time till removal of fixate ranged from 5 to 11 months. Follow up was at least 3 years after Ilizarov fixator removal.

Results: Most flaps survived, two had marginal necrosis and one superficial epidermal necrosis. No complications were related to the donor site, flap, or by immobilization. Each patient resumed essentially normal gait and activity without stiffness of joints related to the flap or Ilizarov fixator. Complete failure occurred in one patient due to persistent severe infection and single vessel limb and underwent amputation.

Conclusion: This study showed how the cross leg fasciocutaneous flap can be easily raised through an Ilizarov ring and can be transposed anteriorly to cover soft tissue defects in the lower third of the leg without losing the stability of the construct.

Key words: Cross leg flap, Ilizarov fixator, lower tibial defect.

\section{Introduction:}

The anatomical features of the lower third of the leg make the wound coverage of the soft tissue loss in a complex injury a challenging problem for orthopedic and plastic surgeons. The bones of the lower third are vulnerable to injury. Due to the paucity of soft tissues around them, the fractures that occur are often open. Most muscles become tendons at that level and in the case of soft tissue loss, skin graft may not suffice and flap cover becomes mandatory. The three major arteries to the leg, anterior and posterior tibial, and peroneal are in closed compartments and they do not have significant communications between them, the poor vascularization and subsequent poor healing encountered in these regions make the coverage of the wounds in lower third leg a challenging problem, and demand detailed knowledge of the local anatomy to select the best surgical alternative for each patient. ${ }^{1}$

The primary goal in limb salvage is definite wound closure by using appropriate flaps. Since the cross-leg flap was first described by Hamiltonin $1874,{ }^{2}$ it was the optimal option for covering defects of the leg and foot for 
a long time. ${ }^{3}$ During World War II, this flap was widely used, with satisfying results. With the advent of microsurgical techniques, the cross-leg flap was used less frequently. Since the 1990s, microvascular surgery has been regarded by many centers as the gold standard for salvaging severely traumatized lower extremities. ${ }^{4}$ However, free flap operations are technically highly demanding, expensive, time consuming and are not applicable for all the patients. First, free flaps cannot not be used in patients who suffer extensive lower extremity injury with axial vessel damage and who have a history of previous trauma or vessel thrombosis. In addition, free flaps are not suitable for patients with severe peripheral vessel diseases and for those whose general conditions do not allow surgical procedures of long duration. Third, electrical injury, single vessel extremities, and extremities receiving radiotherapy after tumor resection are relative contraindications for free flap. ${ }^{5}$ In these conditions, the cross-leg flap could be a good choice for reconstructing the defects as local fasciocutaneous and myocutaneous flaps are often not available.6,7 Many refinements of the cross-leg procedure have been reported, such as the cross-leg tibial posterior perforator flap, ${ }^{8}$ distally based sural artery fasciocutaneous cross-leg flap, ${ }^{9}$ and the saphenous neurofasciocutaneous flap. ${ }^{10}$ These improvements profoundly increase flexibility of the cross-leg flap and make it versatile for treating lower extremity wounds. The inclusion of fascia in the flap makes length-to-width ratio 3:1 perfectly safe.

This allows much greater area of skin to be transferred with much more freedom of leg position. ${ }^{11}$

Open fractures of the tibia, with associated vascular injuries, have historically had a very poor outcome, this poor prognosis has prompted some to call for early amputation in select cases. ${ }^{12}$ Ilizarov external fixation has proven to be a valuable method for treating open tibial fractures. The ability of the frame to stabilize a fracture, provide compression at the fracture site, and allow access to the soft tissues reconstruction makes it an integral tool in the management of severe tibia fractures with or without bone loss. Metaphyseal fractures with significant shaft extension and fractures with short periarticular fragments are examples of situations in which an Ilizarov frame is frequently employed. ${ }^{13}$ Nowadays, the Ilizarov non-free bone plasty and free vascularised autografts have been universally acknowledged as two alternative ways for bone defect management. ${ }^{14}$ Ideally, the Ilizarov bone plasty implies a gradual transport of a vascularised osteotomised bone autograft that is enveloped into soft tissues and induces guided tubular bone formation in the defect gap both in length and shape. The system of Ilizarov bone reconstruction for defect management is based on two main techniques; lengthening of a defect fragment through an osteotomy with consolidation of the transported fragment at the docking site, and gradual tibiofibular synostosis or gradual tibialisation of the fibula. ${ }^{15}$

When large areas of bone are exposed soft tissue cover of such an area will reduce the amount of bone to be lengthened and also provide adequate vascularity to the underlying bone and decrease incidence of osteomyelitis. ${ }^{16}$ Because the cross-leg flap, which is located in a lower rung of the reconstructive ladder Figure(1), is less technically demanding, demonstrates greater safety and could provide stable coverage for different defects in lower third leg with few complications. ${ }^{17}$ Even should the flap fail, no significant bridges have been burnt and all the other surgical options remain viable. Traditionally, cross-leg flaps have been problematic because of difficulties with immobilization and positioning of the extremities from the time of initial coverage to detachment. The use of external fixator for immobilization circumvents many of these problems and facilitates the use of cross-leg flaps in patients in whom free tissue transfer may not be optimal. ${ }^{18}$

In this article we used cross-leg flap as a first choice instead of a free flap for soft tissue reconstruction in 9 patients with grade IIIB, $\mathrm{C}$ open lower third tibial fracture Table(1), along with $3 / 8$ modified Ilizarov ring fixator that had dual effects, first to act on bone and 
second to maintain positioning of two legs till division of the flap.

\section{Patients and methods:}

This prospective study was conducted between 2008 and 2012 at Nasser Institute and El-Helal hospital. Nine patients with post-traumatic combined bone and soft tissue detects affecting distal third tibia were treated. Informed written consent was taken from all patients. High energy trauma was the mechanism in all injuries, 2 motor car accidents, 6 motor cycles and one patient was injured by a factory machine. All patients were males between 18 and 42 years old. Right side distal tibial third was affected in 5 patients and left side in 4. Four patients were Gustilo type IIIB with extensive periosteal stripping and 5 patients Gustilo type IIIC with anterior tibial artery injured in 4 and posterior tibial in one. Bone defect was present in 6 patients, in 2 or them bone loss was primary at time of injury and in other 4 patients bone loss was iatrogenic after aggressive debridement to remove infected sequestrated and avascular bone fragments. The size of bone defect ranged from 4-7 cm with overlie soft tissue defect . Late presentation (2-5 months after injury) was present in 6 patients, 2 of the soft tissue defect had been covered by local flaps by others but failed. 4 defects could not be covered by local flaps because of the extensive soft tissue injury and were subjected to frequent dressing. One delayed primary after one week and 2 patients presented as acute trauma within 6-12 hours with variable degrees of infection were present in 5 cases. Nerve injury was negative in all patients. Number of previous operations ranged from 2 to 4 in the form of debridement, unilateral fixator and plating associated injuries were present in 5 patients in the form of ipsilateral facture terms in one, contralateral fracture hummers in one and 2 fracture ribs and one abdominal injury to which spleenectomy was done. General condition was satisfactory in all except for anemia in 2 patients that was corrected by fresh blood transfusion preoperative. 2 patients were virus $\mathrm{C}$ infected. Exposure of bone and/or hardware was the major problem in these patients. Summary of patient's data Table(2).

\section{Methods:}

A protocol for sequential staged reconstruction and preoperative planning was arranged by the orthopedic and plastic surgeon in all cases. First stage included aggressive debridement of both bone and soft tissue to remove all infected necrotic soft tissue and bone fragments and creation of healthy trimmed bone, then stability was achieved by application of 3/8 Ilizarov ring modified by the orthopedic surgeon author and applied away from the route of cross-leg flap as directed by the plastic surgeon (mostly antero-lateral position) Figure(2,3a).

In second stage, to design the cross-leg flaps, we took 3 issues into consideration. First, position of the limbs as it is essential to find an appropriate position to make the recipient site as close to the donor site as possible for reducing the bridge segment of the flap, to make the flap lie easily on the defects with minimal tension, least discomfort to the patient and to give way for Ilizarov rings and wires to be applied in proper level according to the pre-surgical plane. Second, is the size, location, and shape of the defects, all defects in the study were over lower third tibia with underlying bone fracture and, or defect. Third consideration was the choice of flap, in our study random-patterned flap was the choice. The principal donor site of random-patterned cross-leg flaps was the posterior area of the leg (from the lower edge of the popliteal fosse to the upper edge of the Achilles tendon). A wide base, not less than one-half of the length, was necessary for random flaps. It was recommended to raise the underlying fascia together to improve the blood supply of the flaps. When the flap was ready for mounting to the site of combined defect the Ilizarov surgeon started to apply another 3/8 Ilizarov frame on the donor leg side. Then, the crossleg flap was harvested to cover the soft tissue defect and after reaching the desired tension on the flap, satisfactory vascularity with no kinking, the orthopedic surgeon was asked to inter-connect both Ilizarof frames by crossing 
rods reaching between male posts connected with nylon nuts to allow micro-adjustment and momentary change until reaching desired position satisfactory to the plastic surgeon as regard tension on his flap then tightening of nuts was done to achieve stable cross-ilizarov frames. The donor site was covered with split thickness skin graft, this stage lasted for 2-3 weeks till the third stage Figure(3b, c).

The third stage began about 15 days postoperatively by training for flap division through ligation of the proximal part of the flap pedicle. If the pedicle could be legated more than 45 minutes without ischemia or congestion appearance, it could be safely divided Figure(4). In general, the pedicles were divided at $18 \pm 2$ days (range 15 to 21 days) postoperative. After flap division the Ilizarov frame was removed from the donor site, the $3 / 8$ ring on the affected side with bone defect was converted into a complete Ilizarov ring then to and proximal corticotomy was done to start segment transfer after 10 days to cover the bone defect and patient was allowed to weight bear 3 weeks after for skin graft and flap to be taken and start joint range physiotherapy Figure(5, 6).

\section{Results:}

Hospital stay duration ranged from 3-4 weeks. Cross leg flap was divided at $18 \pm 2$ days (range 15 to 21 days). Follow up was at least 3 years after Ilizarov fixator removal (with exception of one patient lost during follow up). Follow up was done at regular visits in out-patient clinic weekly till end of bone transport then every 3 weeks till removal of frame. Assessment in each visit was done clinically and radiologically by plain $\mathrm{X}$ ray. Total treatment time till removal of fixate ranged from 5 to 11 months according to the size of bone defect and rate of consolidation. 2 patients needed further surgical interference, one of the flap recession and other needed freshening and bone graft at docking site. 8 patients out of 9 achieved successful combined reconstruction with union and cross flap cover. 4 patients needed simple adjustment of connecting rods between cross Ilizarov frames to allow better position for cross flap vascularity; this was carried on in the ward during routine regular flap assessment by plastic surgeon in presence of Ilizarov orthopedic surgeon ready to do any necessary adjustment. Complications included regular Ilizarov technique complications such as superficial pin tract infection in 6 patients that was managed by pin care and antibiotics. Residual shortening occurred in 2 patients and was about 1.5 and $2.5 \mathrm{~cm}$ and was accepted by both. Residential infection and sinus discharging pus in one and non union at docking site in 2 and was treated by freshening and bone grafting done through incision at flap border away from pedicle and was done by plastic surgeon. Ankle stiffness occurred in one patient due to soft tissue contracture. Delayed consolidation at distraction gap occurred in 2 patients and was treated by BMAT (bone marrow aspiration transfer). Residual deformity occurred in two patients in the form of varus 7 and 9 degrees and was accepted by the patients. Residual equinity occurred in one patients treated by physiotherapy. Most flaps have survived without complications. Flap necrosis occurred in 2 patients. 1 suffered partial flap necrosis and a skin graft was used for wound closure after sharp debridement and regular dressing and the other patient suffered marginal necrosis and the surface had epithelialized within 1 week. 3 patients developed osteomyelitis in spite of total flap survival. All of these 3 patients suffered from wound infection when admitted. Complete failure occurred in one patient due to persistent severe infection and single vessel limb and underwent amputation.

\section{Discussion}

Worldwide scholars have been dedicated for decades to the foundation of optimal treatment protocols for complex lower extremity wounds and have made great contributions. Currently, wound lavage, thorough debridement, skeletal stabilization, and healthy soft tissue coverage have been widely recognized as the surgical principles. In the distal tibia, free flaps were the preferred flaps for covering large soft tissue defects. 
Local fasciocutaneous flaps described by Ponten have decreased the need for muscular and free flaps in reconstruction. ${ }^{19}$ However in the presence of a ring fixator it is difficult to perform free flaps and local fasciocutaneous flaps. Cross leg flaps, in spite of the inherent morbidity associated with the procedure, continue to remain as a useful technique for the coverage of wounds in the lower third of the leg. They are particularly useful when free

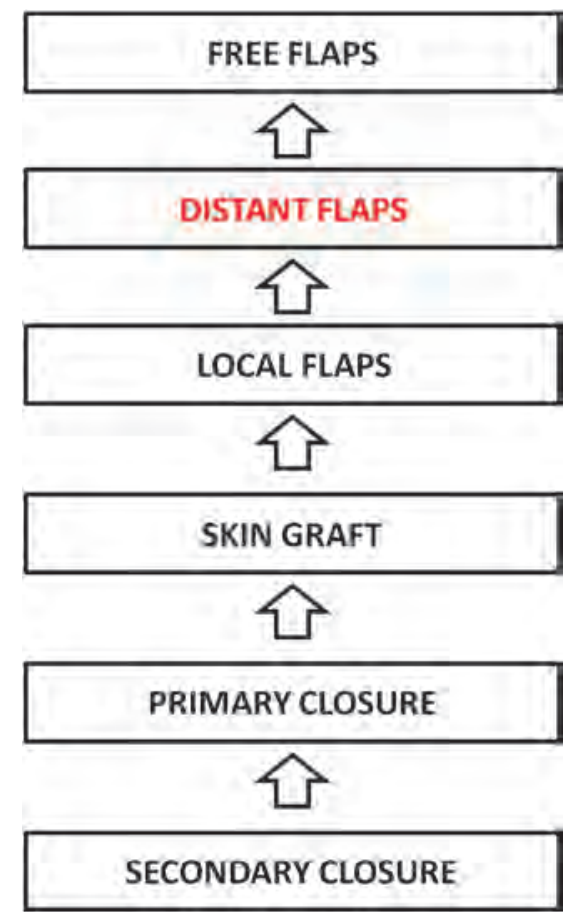

Figure (1): Reconstructive ladder: the crossleg flap was categorized in the distant flaps, which is on a lower rung than free flaps. flap and local flap are not available, a condition that frequently happened in complex trauma of type IIIB, C Gustilo type. ${ }^{20}$ The cross-leg flap being less technically demanding and easily handled as compared with free flap helps the surgeon to close the traumatic wound as soon as possible, thereby decreasing the incidence of complications, especially infection. Timely wound closure could increase the possibility for lower extremity salvage. Aydin, ${ }^{21}$
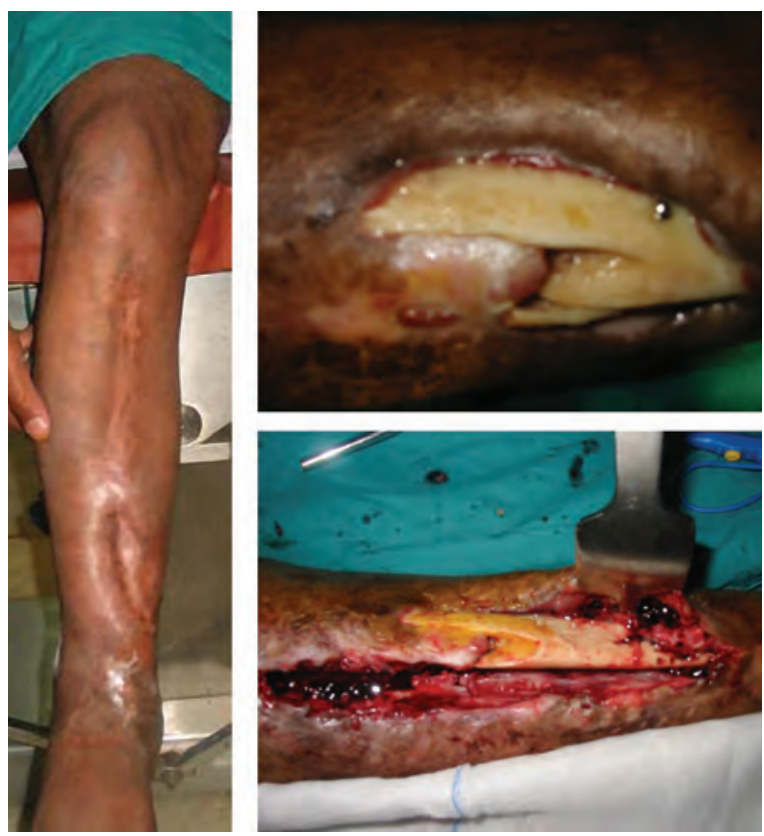

Figure (2): 40 year patient with delayed nonunited infected combined lower third tibial fracture with failed local flap, aggressive debridement of both bone and soft tissue was done to remove all infected necrotic soft tissue, bone fragment till creation of healthy trimmed bone and soft tissue.

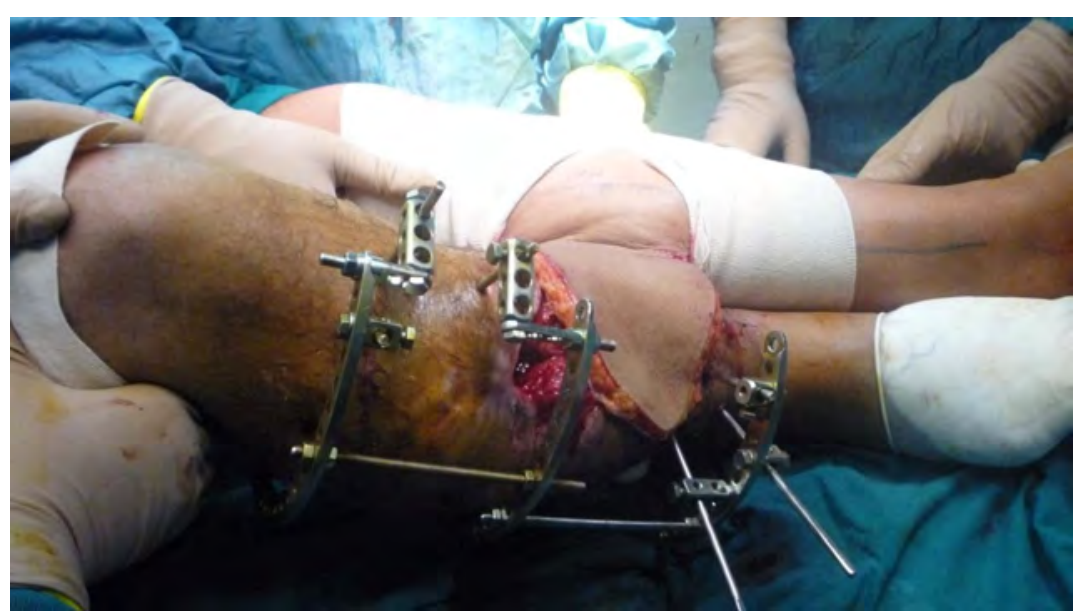

Figure (3a): Stage II reconstruction; 3/8 Ilizarov frame mounted and cross leg flap was harvested and limb position was adjusted. 


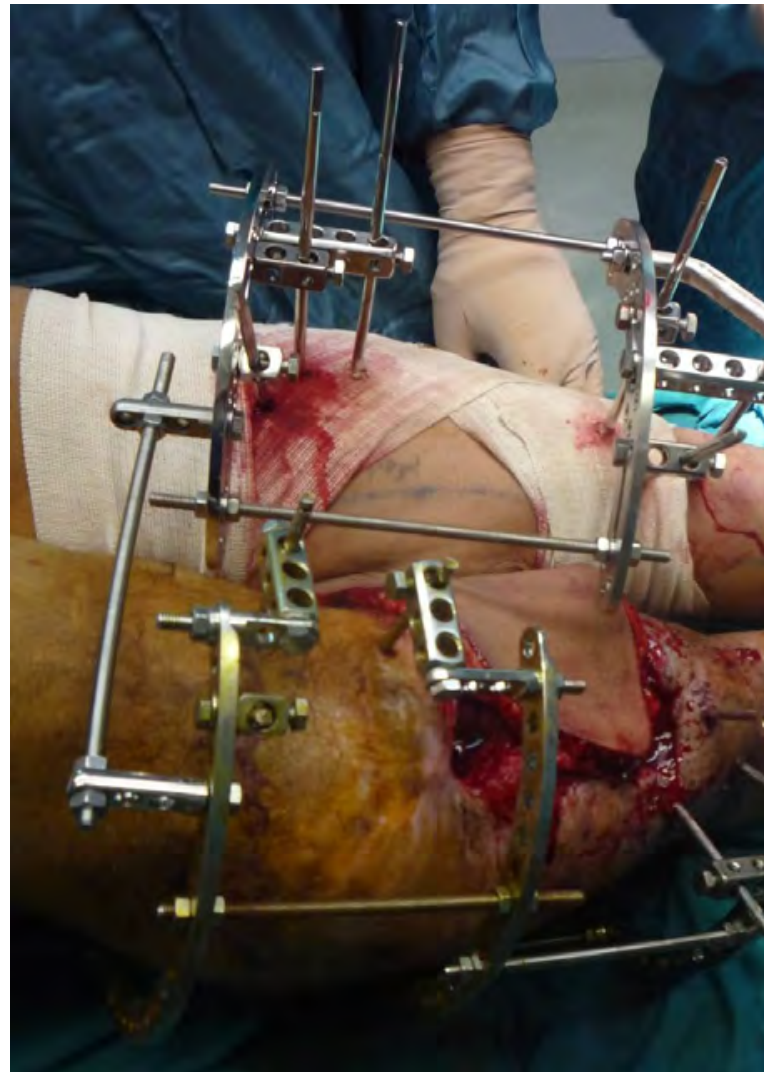

Figure (3b): Contra lateral Ilizarov frame mounted and cross-connecting rods were bridged then cross leg flap covered soft tissue defect and sutured in optimum position then cross connection was tightened.

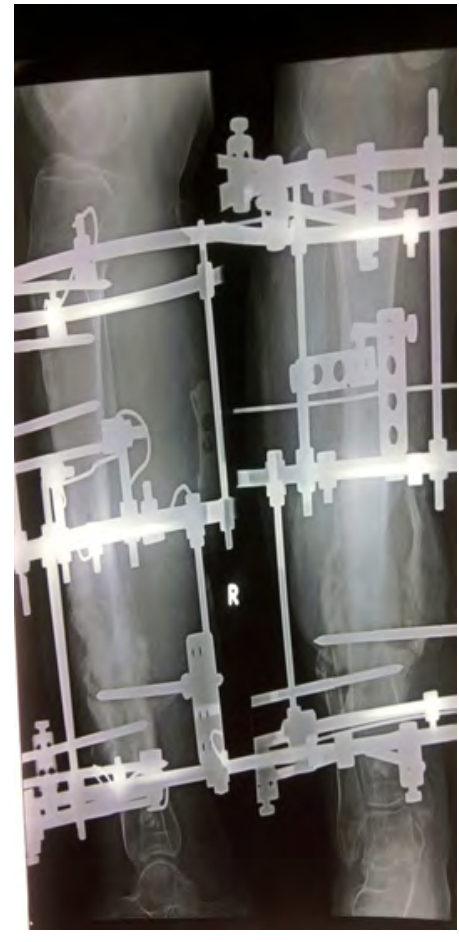

Figure (3c): Plain $X$ ray after application of Ilizarov frame

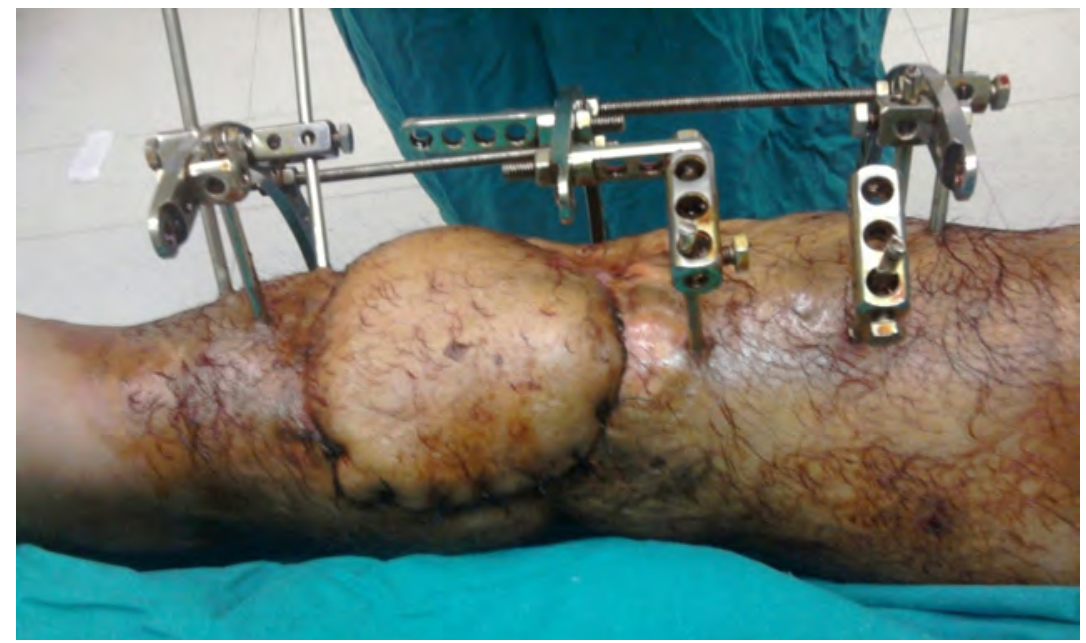

Figure (4): Stage III, 21 days after cross leg Ilizarov, the contrateral frame removed, flap separated and 3/8 Ilizarov frame to be completed to full ring.

reported experience of distally pedicled sural fasciocutaneous cross-leg in 6 children who suffered from crush injuries, and all the flaps survived without complications. Bhattacharya and Reddy, ${ }^{22}$ reported 12 cases using cross-leg flaps for wound coverage, and marginal necrosis within $2 \mathrm{~cm}$ occurred in 2 patients. No flap loss was reported in this article. In our study, we used random pattern cross leg flap to cover lower third 


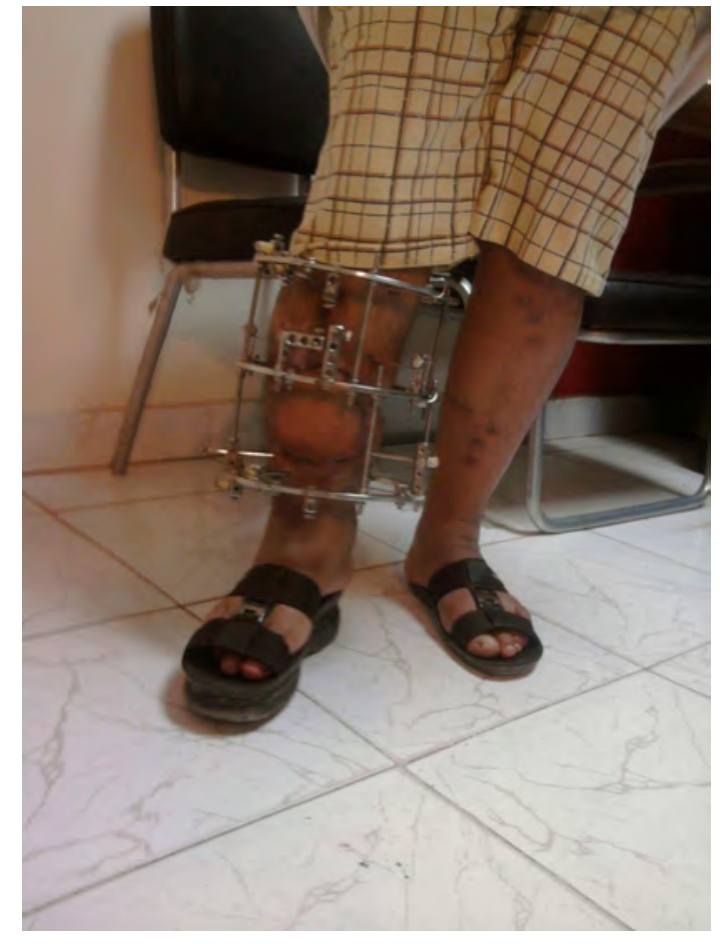

Figure (5): After full-ring Ilizarov frame and full weight bearing.

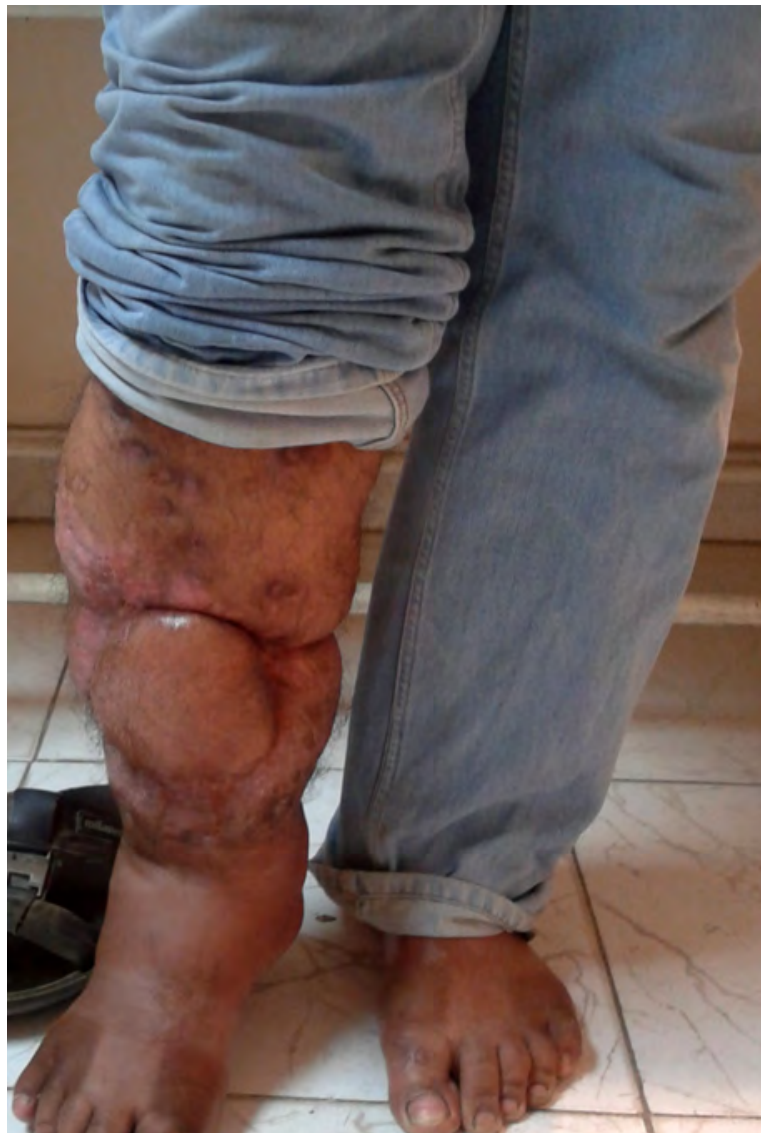

Figure (6): 10 months after cross- leg Ilizarov full weight bearing and satisfactory flap.

on the donor leg and was inter-connected with main Ilizarov frames by crossing rods reaching between male posts connected with nylon nuts to allow micro-adjustment and momentary change until reaching desired satisfactory position. This modification overcame the disadvantage of the cast as regard infection, difficult dressing, loose or tight cast and difficult visualization of the viability of the flap and flap appearance after pedicle training.

In open tibial fracture, early aggressive debridement of nonviable tissues, stabilization with an Ilizarov external fixator, and either primary or delayed primary closure followed by early mobilization and weight bearing is a sound treatment method for complex injuries. $^{24}$ Acute shortening, using the Ilizarov technique followed by progressive lengthening, is one of the methods used to deal with complex fractures combined with severe soft tissue injuries. ${ }^{25}$ Despite technical difficulties and problems associated with 
Table 1: Open fracture: Gustilo classification

\begin{tabular}{|c|l|l|}
\hline \multicolumn{2}{|l|}{ Gustilo Classification } \\
\hline I & Low energy, wound less than $1 \mathrm{~cm}$ \\
\hline II & Wound greater than $1 \mathrm{~cm}$ with moderate soft tissue damage \\
\hline \multirow{2}{*}{ III } & High energy wound greater than $1 \mathrm{~cm}$ with extensive soft tissue damage \\
\cline { 2 - 3 } & IIIA & Adequate soft tissue cover \\
\cline { 2 - 3 } & IIIB & Inadequate soft tissue cover \\
\cline { 2 - 3 } & IIIC & Associated with arterial injury \\
\hline
\end{tabular}

Table 2: Clinical data of patients

\begin{tabular}{|c|c|c|c|c|c|c|c|c|c|}
\hline 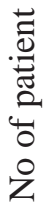 & $\stackrel{8}{<0}$ & 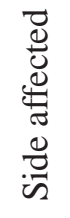 & 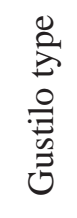 & 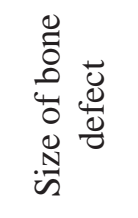 & 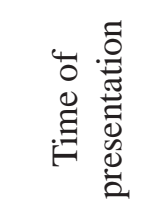 & 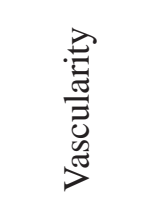 & $\frac{.00}{\mathscr{U}}$ & 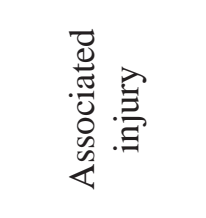 & 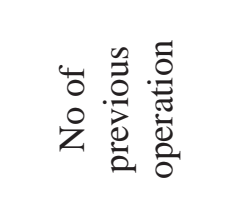 \\
\hline 1 & 35 & Rt. & IIIB & $\begin{array}{l}\text { Average } \\
4-7 \mathrm{~cm}\end{array}$ & $\begin{array}{c}\text { Delay2-5 } \\
\text { ms, } \\
\text { secondary }\end{array}$ & Intact & +ve & -ve & $\begin{array}{l}\text { Failed local } \\
\text { flap }\end{array}$ \\
\hline 2 & 20 & Lt. & IIIC & - & Acute & $\begin{array}{c}\text { Anterior } \\
\text { tibial }\end{array}$ & -ve & $\begin{array}{l}\text { Contralateral } \\
\text { femur }\end{array}$ & $\begin{array}{c}\text { Intramedullary } \\
\text { nail }\end{array}$ \\
\hline 3 & 37 & Rt. & IIIC & - & $\begin{array}{c}\text { Delay2-5 } \\
\text { ms } \\
\text { primary }\end{array}$ & $\begin{array}{c}\text { Anterior } \\
\text { tibial }\end{array}$ & +ve & Rib fracture & Debridement \\
\hline 4 & 24 & Rt. & IIIB & - & $\begin{array}{l}\text { Delay2-5 } \\
\text { ms, } \\
\text { primary }\end{array}$ & Intact & +ve & -ve & Debridement \\
\hline 5 & 37 & Lt. & IIIB & - & $\begin{array}{c}\text { Delay } 1 \\
\text { week }\end{array}$ & Intact & -ve & -ve & -ve \\
\hline 6 & 42 & Lt. & IIIC & - & Acute & $\begin{array}{c}\text { Anterior } \\
\text { tibial }\end{array}$ & -ve & Abdominal & Spleenectomy \\
\hline 7 & 40 & Rt. & IIIC & - & $\begin{array}{l}\text { Delay2- } \\
\text { 5ms, } \\
\text { secondary. }\end{array}$ & $\begin{array}{l}\text { Posterior } \\
\text { tibia }\end{array}$ & +ve & Rib fracture & $\begin{array}{l}\text { Failed local } \\
\text { flap }\end{array}$ \\
\hline 8 & 39 & Rt. & IIIB & - & $\begin{array}{c}\text { Delay2-5 } \\
\text { ms, } \\
\text { primary }\end{array}$ & Intact & -ve & -ve & -ve \\
\hline 9 & 30 & Lt. & IIIC & - & $\begin{array}{c}\text { Delay2-5 } \\
\text { ms, } \\
\text { primary }\end{array}$ & $\begin{array}{l}\text { Anterior } \\
\text { tibia }\end{array}$ & +ve & $\begin{array}{l}\text { Humerus } \\
\text { fracture }\end{array}$ & Debridement \\
\hline
\end{tabular}

pin-tract infections, the Ilizarov external fixator may be the preferred technique in open tibial fractures because of high union rates, the use of thin K-wires with minimal traumatic effect, and more successful functional results. ${ }^{26}$ The most frequent complication was pintract infections. ${ }^{26}$ In this article complications included regular Ilizarov technique complications such as superficial pin tract infection in $66 \%$ patients that was managed by pin care and antibiotics. Accepted residual shortening (1.5 and $2.5 \mathrm{~cm}$ ) occurred in $22 \%$. Ankle stiffness occurred in $22 \%$ of patients due to soft tissue contracture treated by physiotherapy. Residential infection and sinus discharging pus occurred in $11 \%$ and non union at docking site in $22 \%$ and was treated by freshening and bone 
grafting. Delayed consolidation at distraction gap occurred in $22 \%$ of patients and was treated by BMAT (bone marrow aspiration transfer) Residual deformity occurred in 22\% patients in the form of varus 7 and 9 degrees and was accepted by patients.

\section{Conclusion:}

On the basis of our results, we suggest adopting this method for functional limb salvage after extensive complex lower third leg injury. The cross-leg flap is a safe reliable alternative to free tissue transfer in certain situations of lower-limb trauma, and can be handled easily with modified $3 / 8$ ring Ilizarov frame which is safe, versatile and effective in providing stability, bone lengthening and allowing early rehabilitation

\section{Reference}

1- Yazar S, Lin CH, Wei FC. One-stage reconstruction of composite bone and softtissue defects in traumatic lower extremities. Plast Reconstr Surg 2004; 114 : 1457-1466.

2- Stark RB. The cross-leg flap procedure. Plast Reconstr Surg 1952; 9: 173-204.

3- Morris AM, Buchan AC. The place of the cross-leg flap in reconstructive surgery of the lower leg and foot: A review of 165 cases. $\mathrm{Br}$ J Plast Surg 1978; 31: 138-142.

4- Francel TJ, Vander Kolk CA, Hoopes JE, et al. Microvascular soft-tissue transplantation for reconstruction of acute open tibial fractures: Timing of coverage and long-term functional results. Plast Reconstruct Surg 1992; 89: 478-487; discussion, 488-489.

5- Ogun TC, Arazi M, Kutlu A. An easy and versatile method of coverage for distal tibial soft tissue defects: $J$ Trauma 2001; 50: 53-59.

6- Parrett BM, Matros E, Pribaz JJ, et al. Lower extremity trauma: trends in the management of soft-tissue reconstruction of open tibiafibula fractures. Plast Reconstruct Surg 2006; 117: 1315-1322; discussion 1323-1324.

7- Spector JA, Levine S, Levine JP. Free tissue transfer to the lower extremity distal to the zone of injury: Indications and outcomes over a 25-year experience. Plast Reconstruct Surg 2007; 120:952-959.

8- Georgescu AV, Irina C, Ileana M. Cross-leg tibial posterior perforator flap: Microsurgery 2007; 27: 379-383.

9- Basile A, Stopponi M, Loreti A, et al. Heel coverage using a distally based sural artery fasciocutaneous cross-leg flap: Report of a small series. J Foot Ankle Surg 2008; 47: 112-117.

10- Yildirim S, Akan M, Giderodglu $\mathrm{K}$, et al. Use of distally based saphenous neurofasciocutaneous and musculofasciocutaneous cross-leg flaps in limb salvage: Ann Plast Surg 2001; 47: 568-574.

11- Calhoun JH, Gogan WJ, Beraja V, Howard RJ, Oliphant JR. Dynamic axial fixation for immobilization of cross-leg flaps in chronic osteomyelitis. Ann Plast Surg 1989; 23 : 354-356

12- Hansen ST. The type IIIC tibial fracture. $J$ Bone Joint Surg 1987; 69A:799-800.

13- Ilizarov GA. The treatment of fractures. In: Perosseous Osteosynthesis, Berlin, SpringerVerlag; 1992: 369-452.

14- Yokoyama K, Itoman $\mathrm{M}$, Nakamura K, Tsukamoto T, Saita Y, Aoki S Free vascularized fibular graft vs. Ilizarov method for posttraumatic tibial bone defect. $J$ Reconstr Microsurg (2001) 17(1): 17-25.

15- El-Gammal TA, Shiha AE, El-Deen MA, ElSayed A, Kotb MM, Addosooki AI, Ragheb YF, Saleh WR Management of traumatic tibial defects using free vascularized fibula or Ilizarov bone transport: A comparative study. Microsurgery (2008) 28(5):339-346.

16- Polyzois D, Papachristou G, Kotsiopoulos K, Plessas S. Treatment of tibial and femoral bone loss by distraction osteogenesis. Experience in 28 infected and 14 clean cases. Acta Orthop Scand Suppl 1997; 275: 84-88.

17- de Almeida OM, Monteiro AA Jr, Neves RI, de Lemos RG, Braz JC, Brechtbuhl ER, et al, editors. Distally based fasciocutaneous flap of the calf for cutaneous coverage of the lower leg and dorsum of the foot. Ann Plast Surg. 2000; 44: 367-74.

18- Velazco A, Fleming LL, Nahai F. Soft-tissue reconstruction of the leg associated with the use of the Hoffmann external fixator. $J$ Trauma. 1983; 23: 1052-1057.

19- Ponten B. The fasciocutaneous flap: Its use in soft tissue defects of the lower leg. $\mathrm{Br} J$ Plast Surg 1981; 3: 215-220.

20- Chen H, El-Gammal TA, Wei F, Chen H, Noordhoff MS, Tang Y. Cross-leg free flaps for difficult cases of leg defects: Indications, pitfalls, and long-term results. Trauma.1997; 43: 486-491.

21- Guzo A, Ozyigit T, Ozsoy Z. Use of distally 
pedicled sural fasciocutaneous cross-leg flap in severe foot and ankle trauma: A safe alternative to microsurgery in very young children. Ann Plast Surg 2005; 55: 374 -377.

22- Bhattacharya V, Reddy GR. Retrograde perforator-based crossleg fasciocutaneous flaps for distal leg and foot defects. Plast Reconstruct Surg 2006; 117: 1662-1664.

23- Georgescu AV, Irina C, Ileana M. Cross-leg tibial posterior perforator flap. Microsurgery 2007; 27: 379-383.

24- Ong CT, Choon DS, Cabrera NP, Maffulli N.
The treatment of open tibial fractures and of tibial non-union with a novel external fixator. Injury 2002; 33(9): 829-834.

25- Mseddi MB, Mseddi M, Siala A, et al. Ilizarov fixation of supramalleolar fractures. Rev Chir Orthop Reparatrice Appar Mot 2005; 91(1): 58-63.

26- Inan M, Tuncel M, Karaoglu S, Halici M. Treatment of type II and III open tibial fractures with Ilizarov external fixation. Acta Orthop Traumatol Turc 2002; 36(5): 390-396. 